\title{
Squared frequency-Kt/V: a new index of hemodialysis adequacy-correlation with solute concentrations by computer simulation
}

\author{
Kaya Murakami ${ }^{1}$, Kenichi Kokubo ${ }^{1,2,3^{*}}$, Minoru Hirose ${ }^{1,2}$, Kozue Kobayashi $^{1,2}$ and Hirosuke Kobayashi ${ }^{1,2}$
}

\begin{abstract}
Background: In patients undergoing home dialysis, conventionally, Kt/V has been regarded as an index of the removal efficiency per dialysis session. However, more recently, it has been considered that the hemodialysis product $(\mathrm{HDP})$, rather than the $\mathrm{Kt} / \mathrm{V}$, is better associated with the clinical symptoms and outcomes in patients undergoing short daily dialysis or nocturnal dialysis. Nevertheless, the HDP lacks a theoretical background, and it does not take into consideration the dialyzer clearance or patient's body size. The aims of the present study were to clarify the theoretical validity of HDP focusing on its association with solute concentration by computer simulation and to propose a new index of hemodialysis adequacy.

Methods: We used compartment models and calculated the time course of urea and $\beta_{2}$ microglobulin $\left(\beta_{2} M G\right)$ concentrations to determine the peak concentrations and time-averaged concentrations at varying dialysis frequencies ( $n=2-7$ sessions/week) and durations of dialysis per session ( $t=1$ to $8 \mathrm{~h}$ dialysis sessions).

Results: It was found that the peak concentrations of urea and $\beta_{2} M G$ were significantly correlated with the HDP. Based on this, we theoretically extracted the factor related to the peak concentration and defined the squared frequency-Kt $/ \mathrm{V}$ $(s f-K t / M)$, as a new index for determining hemodialysis adequacy $\left(s f-K t / V=n^{2} K t / V ; K\right.$, clearance; $V$, solute distribution volume; $n$, frequency; $t$, dialysis time); this index was well correlated with the peak concentrations of urea and $\beta_{2} M G$, even when the values of $K$ and $V$ were changed.

Conclusions: Since the $s f-K t / V$ is an index that reflects peak concentrations of urea and $\beta_{2} M G$, which takes into account the dialysis frequency, session duration, dialyzer clearance, and the body weight of the patient, it will be a very useful tool for determining appropriate dialysis schedules and dialysis conditions for individual patients.
\end{abstract}

Keywords: Kt/V, Hemodialysis product, Adequacy of dialysis, Home hemodialysis

\section{Background}

Home hemodialysis has the advantage that dialysis schedule (frequency and duration of dialysis) can be changed at the patients' own convenience. Many modalities of dialysis suitable for home hemodialysis have been proposed, including short daily dialysis [1], nocturnal dialysis [2-5], and daily nocturnal dialysis [6]. Home hemodialysis has been reported to be linked to increased survival $[1,7,8]$, better blood pressure control [2], reduced left ventricular mass [4], improved mineral metabolism [4], enhanced

\footnotetext{
* Correspondence: kokubo@kitasato-u.ac.jp

${ }^{1}$ Kitasato University Graduate School of Medical Sciences, Sagamihara, Japan

${ }^{2}$ Kitasato University School of Allied Health Sciences, Sagamihara, Japan

Full list of author information is available at the end of the article
}

quality of life $[7,8]$, and lower cost $[2,3,5]$. In home hemodialysis, since the dialysis schedule can be flexibly determined, a reliable index useful for determining the appropriate home dialysis modality, dialysis schedule (frequency and duration), and dialysis treatment conditions is required.

The $K t / V$ is a well-known index of the removal efficiency per dialysis session. To compare different dialysis modalities, the standard $K t / V$ was proposed as an index that can be uniformly used to measure and explicitly compare dialysis doses [9-11]. The use of this index was recommended by the National Kidney Foundation Kidney Disease Outcomes Quality Initiative (KDOQI) guidelines [12] in 2006 and also by the most recent KDOQI in 2015

(C) The Author(s). 2019 Open Access This article is distributed under the terms of the Creative Commons Attribution 4.0 International License (http://creativecommons.org/licenses/by/4.0/), which permits unrestricted use, distribution, and 
[13], to evaluate the optimal dialysis dose and schedule for frequent dialysis; however, it was still not widely used, probably because (1) its calculation process is quite complex; (2) the calculation required values of single-pool $K t / V$ and equilibrated $K t / V$ to fit the original definition of standard $K t / V$, a mass generation per unit volume of body fluid normalized by the concentration; and (3) there is little advantage to use standard $K t / V$ as an alternative to $K t / V$ Daugirdas which has already been widely used in daily clinical practices for three times a week schedule.

It was also reported that the hemodialysis product (HDP), rather than the $K t / V$, is better correlated with the clinical symptoms and outcomes in patients undergoing short daily dialysis and nocturnal dialysis, the modalities most often used for home hemodialysis [14]. HDP is an index of the adequacy of hemodialysis proposed by Scribner and Oreopoulos [14] in 2002 as their opinion. This index incorporates the dialysis frequency as an important variable:

$$
\mathrm{HDP}=n^{2} t
$$

where $n$ is the dialysis frequency [times/week], and $t$ is the dialysis time per session [h/session].

HDP has been proposed simply based on the very positive results with more frequent dialysis reported by De Palma et al. [15], Buoncristiani et al. [16], Bonomini et al. [17], Pierratos et al. [2, 3], and Lockridge et al. [18]. The HDP has been shown to be well correlated with the patients' symptoms [14], and fewer symptoms [19-28] in dialysis patients has been reported in the treatment at HDP $>70$, although these are retrospective observational studies where HDP has not been used as a treatment criterion. Use of the HDP as an index of the adequacy of hemodialysis has major limitations: it is an empirical index that lacks a physiological or theoretical background and ignores the effects of the dialyzer clearance and patient's body size. Therefore, although many types of dialyzers (low flux to super high flux) are currently available, it is difficult to select a dialyzer and operating condition suitable for short daily dialysis or nocturnal dialysis on the basis of the HDP.

The purpose of the present study was to explore a new index based on solute removal useful for ascertaining the adequacy of hemodialysis that would incorporate dialysis schedule (frequency and duration), the dialyzer clearance, and patient's body size. To this end, we first sought to identify factors (such as the time-averaged concentrations/peak concentrations) that are strongly correlated with the HDP using a kinetic model. From our results, we developed an index that was also well correlated with these factors and validated the index using a kinetic model.

\section{Methods}

\section{Kinetic model for urea}

We used the single-pool model (Fig. 1a) and calculated the time course of the concentrations of urea to determine the peak concentrations and time-averaged concentrations under various dialysis schedules (Table 1).

The change of the blood urea level during dialysis was calculated using the following equation:

$$
\frac{V d C_{\mathrm{B}}(t)}{d t}=-K_{\mathrm{u}} C_{\mathrm{B}}(t)+G_{\mathrm{u}}
$$

That is, $C_{\mathrm{B}}(t)=\frac{K_{\mathrm{u}} C_{\mathrm{B}}(0)-G_{\mathrm{u}}}{K_{\mathrm{u}}} e^{-\frac{K_{\mathrm{u}} t}{V}}+\frac{G_{\mathrm{u}}}{K_{\mathrm{u}}}$.

And the change of the blood urea level outside the period of dialysis was calculated by the following equation:

$$
\frac{V d C_{\mathrm{B}}(t)}{d t}=-K_{\mathrm{u}} C_{\mathrm{B}}(t)+G_{\mathrm{u}}
$$

That is, $C_{\mathrm{B}}(t)=\frac{G_{\mathrm{u}}}{V} t+C_{\mathrm{B}}\left(t_{1}\right)$

where $C_{\mathrm{B}}$ is the blood urea level, $C_{\mathrm{B}}\left(t_{1}\right)$ is the blood urea level at the end of dialysis, $K_{\mathrm{u}}$ is the urea clearance, and $G_{u}$ is the endogenous production rate of urea. Using these equations, assuming $K_{\mathrm{u}}=0$, and a steady state (we

\section{A}

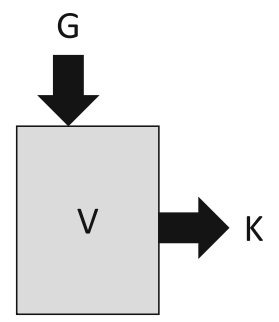

B

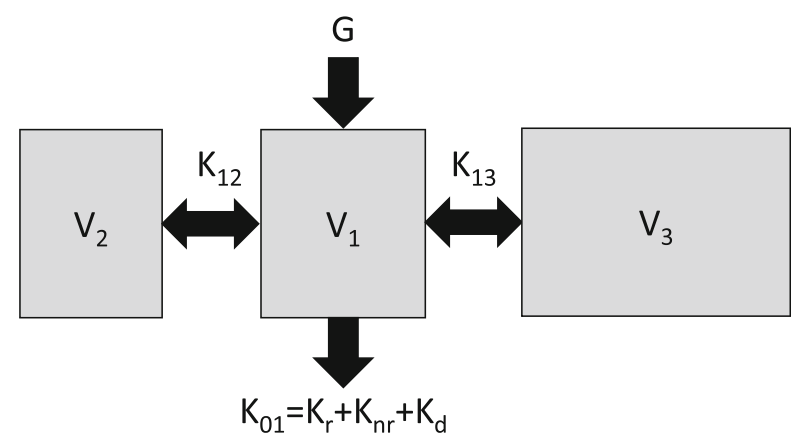

Fig. 1 Schematic diagram of single-pool (one-compartment) model (a) and three-compartment model (b) 
Table 1 Setting conditions in the simulation

\begin{tabular}{llllllllllllllllll}
\hline Group & A4 & A5 & A6 & A7 & A8 & B4 & B5 & B6 & B7 & B8 & C4 & C5 & C6 & C7 & C8 & D3 & D4 \\
Dialysis frequencies [sessions/week] & 2 & 2 & 2 & 2 & 2 & 3 & 3 & 3 & 3 & 3 & 4 & 4 & 4 & 4 & 4 & 5 & 5 \\
Dialysis time per session [h/session] & 4 & 5 & 6 & 7 & 8 & 4 & 5 & 6 & 7 & 8 & 4 & 5 & 6 & 7 & 8 & 3 & 4 \\
HDP & 16 & 20 & 24 & 28 & 32 & 36 & 45 & 54 & 63 & 72 & 64 & 80 & 96 & 112 & 128 & 75 & 100 \\
Group & D5 & D6 & D7 & D8 & E2 & E3 & E4 & E5 & E6 & E7 & E8 & F1 & F2 & F3 & F4 & F5 & F6 \\
Dialysis frequencies [sessions/week] & 5 & 5 & 5 & 5 & 6 & 6 & 6 & 6 & 6 & 6 & 6 & 7 & 7 & 7 & 7 & 7 & 7 \\
Dialysis time per session [h/session] & 5 & 6 & 7 & 8 & 2 & 3 & 4 & 5 & 6 & 7 & 8 & 1 & 2 & 3 & 4 & 5 & 6 \\
HDP & 125 & 150 & 175 & 200 & 72 & 108 & 144 & 180 & 216 & 252 & 288 & 49 & 98 & 147 & 196 & 245 & 294 \\
\hline
\end{tabular}

Time course of changes in the solute concentrations for various dialysis schedule was calculated (the dialysis frequency varied from 2 to 7 per week and/or

dialysis time per session from 1 to $8 \mathrm{~h}$ )

repeatedly calculated the concentrations until the concentrations at the beginning and end of the week were equal), the time courses of the urea concentrations were calculated by the treatment conditions and the production rate of urea [29] (Table 2).

\section{Kinetic model for $\beta_{2}$-microglobulin}

Three-compartment models (Fig. 1b) in which $\beta_{2}$-microglobulin ( $\left.\beta_{2} \mathrm{MG}\right)$ was distributed in a slowly moving pool and fast moving pool were used to calculate the time courses of $\beta_{2} \mathrm{MG}$ concentration under various dialysis schedules (Table 1). The values of total clearance, intercompartmental clearance parameters, and compartmental volumes reported by Odell et al [30] for $\beta_{2}$ MG were used. The equation of mass transfer in each compartment could be expressed by the following equations:

$$
\begin{aligned}
& \frac{V_{1} d C_{1}}{d t}=-\left(K_{01}+K_{12}+K_{13}\right) C_{1}+K_{12} C_{2}+K_{13} C_{3} \\
& +G_{\beta} \\
& \frac{V_{2} d C_{2}}{d t}=K_{12} C_{1}-K_{12} C_{2} \\
& \frac{V_{3} d C_{3}}{d t}=K_{13} C_{1}-K_{13} C_{3} \\
& K_{01}=K_{\mathrm{r}}+K_{\mathrm{nr}}+K_{\mathrm{d}} \\
& V_{\mathrm{d}}=V_{1}+V_{2}+V_{3}
\end{aligned}
$$

where $K_{n} K_{n n}$ and $K_{d}$ are the renal, non-renal, and dialyzer clearance, respectively. The distribution volume, $V_{\mathrm{d}}$, is the sum of the compartmental volumes, and $G_{\beta}$ is the endogenous production rate of $\beta_{2}$ MG. The differential equations were solved numerically using a

Table 2 Treatment conditions used to calculate the time courses of urea concentration using a single-pool model

\begin{tabular}{lll}
\hline Clearance of urea, $K_{u}$ & $90,120,150,180$ & {$[\mathrm{~mL} / \mathrm{min}]$} \\
Endogenous production rate of urea, $G_{u}$ & 6.2 & {$[\mathrm{mg} / \mathrm{min}]$} \\
Fluid volume before the start of dialysis, $V$ & 36,000 & {$[\mathrm{~mL}]$} \\
\hline
\end{tabular}

Runge-Kutta routine, using reported values [30] (Table 3). The time courses of the solute concentrations were calculated by the treatment conditions, such as the mass transfer coefficient between pools, solute production, and clearance of dialyzer.

We compared the correlation between the peak concentrations/time-averaged concentrations of solutes and the HDP, total dialysis time, or squared frequency-Kt/ $V(s f-K t / V)$, by determining the coefficients of determination $\left(R^{2}\right)$, likelihood $(L)$, and Akaike Information Criterion (AIC).

\section{Model fitness}

Regarding HDP $\left(n^{2} t\right)$ and total dialysis time $(n t)$, we compared which one better estimates peak concentration and time-averaged concentration. Wilcoxon's signed-rank sum test was used to check whether there was a significant difference in the absolute value of the difference between the approximate curves calculated by a least squares method and the calculated values by simulation.

Likelihood ratio test was used to compare the HDP $\left(n^{2} t\right.$, degree of freedom is 2$)$ and $s f-K t / V$ (degree of freedom is 4). We compared the fitness between the HDP or the $s f-K t / V$ and the peak concentrations of small molecules at varying dialyzer clearances (Fig. $4 \mathrm{a}, \mathrm{b}$ ), and the fitness between the HDP or the $s f-K t / V$ and the

Table 3 Treatment conditions used to calculate the time courses of $\beta_{2} M G$ concentration using a three-compartment model

\begin{tabular}{lll}
\hline Clearance of $\beta_{2} M G, K_{\beta}$ & $40,60,80$ & {$[\mathrm{~mL} / \mathrm{min}]$} \\
Non-renal clearance, $K_{\mathrm{nr}}$ & 2.82 & {$[\mathrm{~mL} / \mathrm{min}]$} \\
Renal clearance, $K_{\mathrm{r}}$ & 0 & {$[\mathrm{~mL} / \mathrm{min}]$} \\
Intercompartmental clearance, $K_{12}$ & 75 & {$[\mathrm{~mL} / \mathrm{min}]$} \\
Intercompartmental clearance, $K_{13}$ & 28.8 & {$[\mathrm{~mL} / \mathrm{min}]$} \\
Endogenous production rate, $G_{\beta}$ & 0.159 & {$[\mathrm{mg} / \mathrm{min}]$} \\
Fluid volume before the start of dialysis, $V$ & 36,000 & {$[\mathrm{~mL}]$} \\
Volume of compartment 1 per body weight & 53 & {$[\mathrm{~mL} / \mathrm{kg}]$} \\
Volume of compartment 2 per body weight & 39 & {$[\mathrm{~mL} / \mathrm{kg}]$} \\
Volume of compartment 3 per body weight & 109 & {$[\mathrm{~mL} / \mathrm{kg}]$} \\
\hline
\end{tabular}


time-averaged concentrations of urea and $\beta_{2} \mathrm{MG}$ at varying dialyzer clearances (Fig. 4c, d).

First, the maximum log likelihood $(L)$ was calculated from the residual sum of squares of the approximate curves and the calculated values by simulation by the following equation.

$$
\log L=-\frac{N}{2}\left(\log (2 \pi)+\log \sigma^{2}+1\right)
$$

where $\sigma^{2}$ is the maximum likelihood estimator of variance, and $N$ is sample size. The difference of the deviance was calculated by multiplying $\log L$ by -2 ,

$$
\Delta D=-2 \log L_{\mathrm{HDP}}-\left(-2 \log L_{\mathrm{sf}-\mathrm{Kt} / \mathrm{V}}\right)
$$

We performed a chi-square test for $\Delta D$ with a difference of 2 degrees of freedom to compare HDP with $s f-K t / V$ regarding which one would be better for fitting to the peak concentrations of urea and $\beta_{2}$ MG at varying dialyzer clearances.

AIC was also calculated by the following equation:

$$
\mathrm{AIC}=-2 L+2 \times(\text { number of parameters })
$$

When the AIC is smaller, the model is considered to be a better fitting model after taking into account the number of parameters used.

\section{Results}

\section{Search for factors correlated with the HDP}

We assumed that if we could identify the factors that were more strongly correlated with the HDP than with the total weekly dialysis time, we would be able to estimate why HDP $\left(n^{2} t\right)$ is better correlated with the clinical symptoms than the total weekly dialysis time $(n t)$. We focused on the peak concentrations and time-averaged concentrations of solute molecules per week. We used a single-pool model to investigate the kinetics of urea and a three-compartment model to investigate the kinetics of $\beta_{2}$ MG [30].

The time courses of solute concentrations under various dialysis schedules (varying dialysis frequencies from 2 to $7 /$ week and varying dialysis times per session from 1 to $8 \mathrm{~h} /$ session) were calculated (Table 1 ). We determined the peak concentrations and time-averaged concentrations for each solute.

The peak concentrations of all molecules were found to be significantly better correlated with the HDP than with the weekly total dialysis time (Fig. 2). While the time-averaged concentrations of urea were more tightly correlated with weekly total dialysis time than with HDP (Fig. 3). Thus, our results suggested that the HDP is strongly correlated with the peak concentrations of urea and $\beta_{2}$ MG.

The "unphysiological nature" of dialysis may also be demonstrated by the difference between the maximum and minimum concentrations. This parameter was, however, not well correlated with HDP (data not shown).

We propose HDP $\times K / V\left(n^{2} t \times K / V\right)$ as a new index called $s f-K t / V$ (Appendix). This index incorporates both solute removal $(K)$ and fluid volume of the patient $(V)$, whereas the HDP does not. We then investigated whether this index would still be well correlated with the peak concentrations of small molecules when the clearance of the dialyzer was varied. The correlation of the $s f-K t / V$ with the concentrations showed higher $R^{2}$ and lower AIC than that of HDP, and the difference in maximum log likelihood (deviance) was statistically large, meaning that the $s f-K t / V$ showed significantly better correlations with the peak concentrations of small molecules than HDP (Fig. 4). In other words, while the correlations with the HDP became weak when we used a different dialysis clearance, the $s f-K t / V$ still showed strong correlations with the peak concentrations of urea. Since $s f-K t / V$ is obtained by multiplying HDP by $K / V$, that is, the dialyzer clearance and patient's body weight is also considered in the calculation of the $s f-K t / V$; this index is deemed as being a useful new index for comparing the adequacy of dialysis based on solute removal (dialysis dose).

While no precise threshold value of the HDP has been determined based on clinical evidence, HDP $>70$ proposed by Scribner and Oreopoulos [14] is well accepted as being indicative of adequate dialysis. In a patient with a dry weight of $60 \mathrm{~kg}$ (body fluid volume, $36 \mathrm{~L}$ ) undergoing dialysis with a dialyzer providing an average urea clearance of $160 \mathrm{~mL} / \mathrm{min}$ and HDP $>70$ will be equivalent to $s f-K t / V>18.7$.

Assuming that HDP $>70$ is the threshold value for determining the adequacy of dialysis, we would determine the treatment schedules at varying dialyzer clearances (Fig. 5) and varying patient body weights (Fig. 6) that would yield $s f-K t / V$ values of over 20. When conducting dialysis four times a week, 6-h dialysis sessions are enough to obtain an HDP value of over $70\left(4^{2} \times 6=96 ;>70\right)$, regardless of the dialyzer urea clearance. When $s f-K t / V$ is used, and if patient weight was $60 \mathrm{~kg}$, it can be judged that sufficient solute removal would be obtained when the dialyzer clearance is $180 \mathrm{~mL} / \mathrm{min}$ or $150 \mathrm{~mL} / \mathrm{min}$, but equivalent solute removal cannot be obtained with 6-h sessions when the dialyzer urea clearance is $120 \mathrm{~mL} / \mathrm{min}$ or $90 \mathrm{~mL} / \mathrm{min}$ (Fig. 5), which would occur when blood flow rate or dialysate flow rate set to lower value. The appropriate dialysis frequency and dialysis time per session would also be calculated depending on the patient's body weight (Fig. 6). 


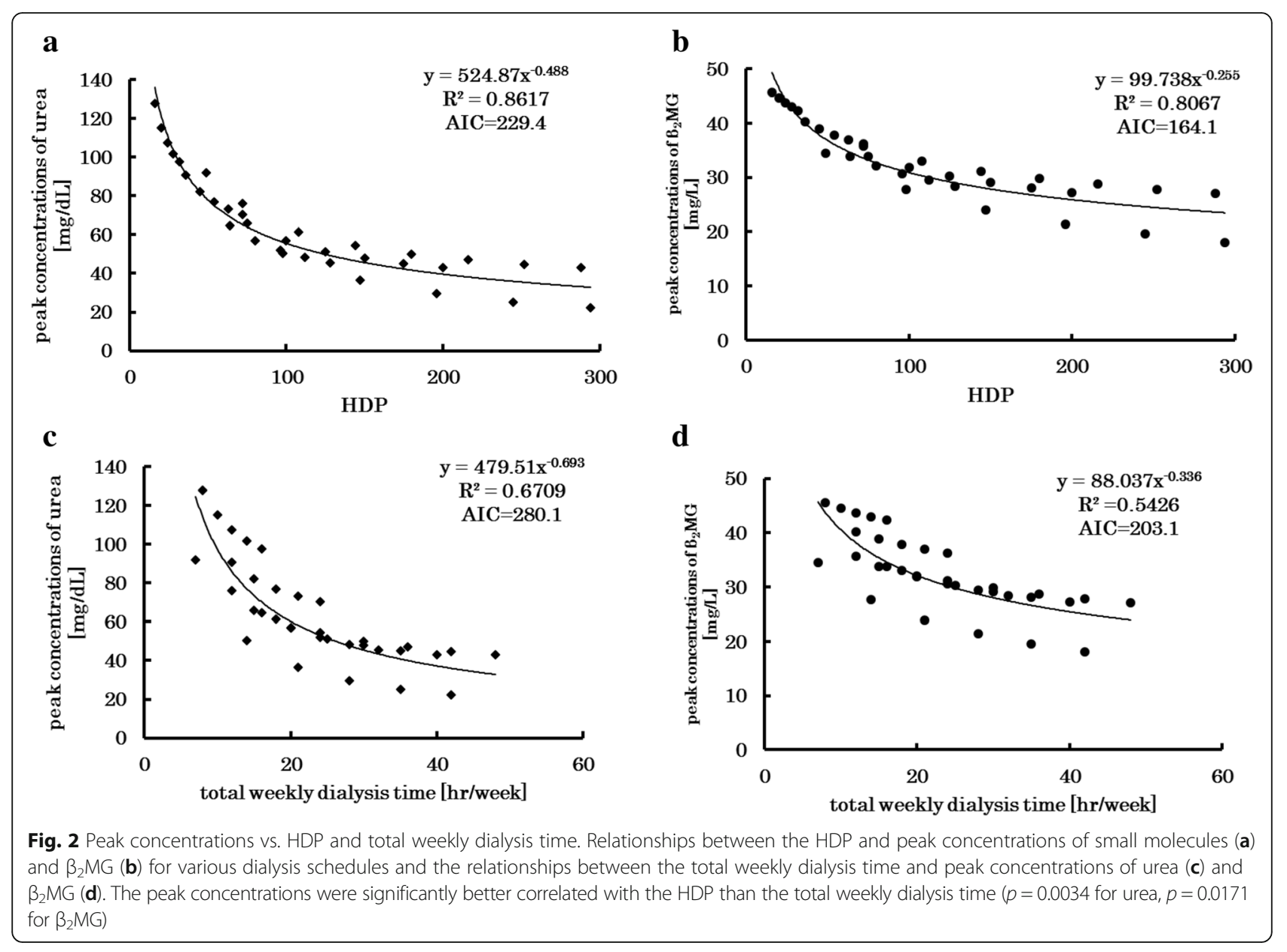

\section{Discussion}

The results of simulations revealed strong correlations of the HDP with the peak concentrations of urea and $\beta_{2}$ MG. Considering these results and the fact that the HDP was empirically related to the clinical symptoms of patients, from viewpoint of solute removal, a large value of HDP would mean smaller peak concentrations, which could explain the reduction of the clinical symptoms.

In the field of pharmacokinetics, the toxicity of the substances is known to be time-dependent and concentration-dependent [31]. The experience that greater the HDP led to lighter the symptoms in dialysis patients [14] and the results we obtained that peak concentration of urea and $\beta_{2}$ MG better correlated with HDP than total dialysis time suggest that the toxicity due to accumulated substances in dialysis patients may concentration-dependent.

Since the results obtained here may be dependent on the parameters listed in Table 3, we have illustrated how the results would change when other values are selected for the relevant parameters. When the parameter changed by about $20 \%$, which was the standard deviation of the measured data in the patients [30] (Table 4), the percent changes of the peak (Table 5) and time-averaged concentrations (Table 6) were determined. Intercompartmental clearances and volumes of the compartments changed the concentration by a few percentage points, and the endogenous production rate of $\beta_{2} \mathrm{MG}$ changed the concentration by $25 \%$. However, the difference among the schedules was only a few percentage points, which would be expected to have had no significant influence on the correlation between the HDP and the peak concentration or time-averaged concentration.

Ultrafiltration and intercompartmental fluid shift may somehow have an influence, especially the concentrations of intermediate-sized molecules like $\beta_{2}$ MG. We checked the effects of ultrafiltration (data not shown). The results were similar to those obtained without taking into consideration ultrafiltration, for both urea and $\beta_{2}$ MG. In regard to intercompartmental fluid shift, we can discuss the results of the effects of the changes in the volumes of the compartments and intercompartmental clearances. The differences in the peak and time-averaged concentrations among the schedules obtained by varying the values of these parameters were 


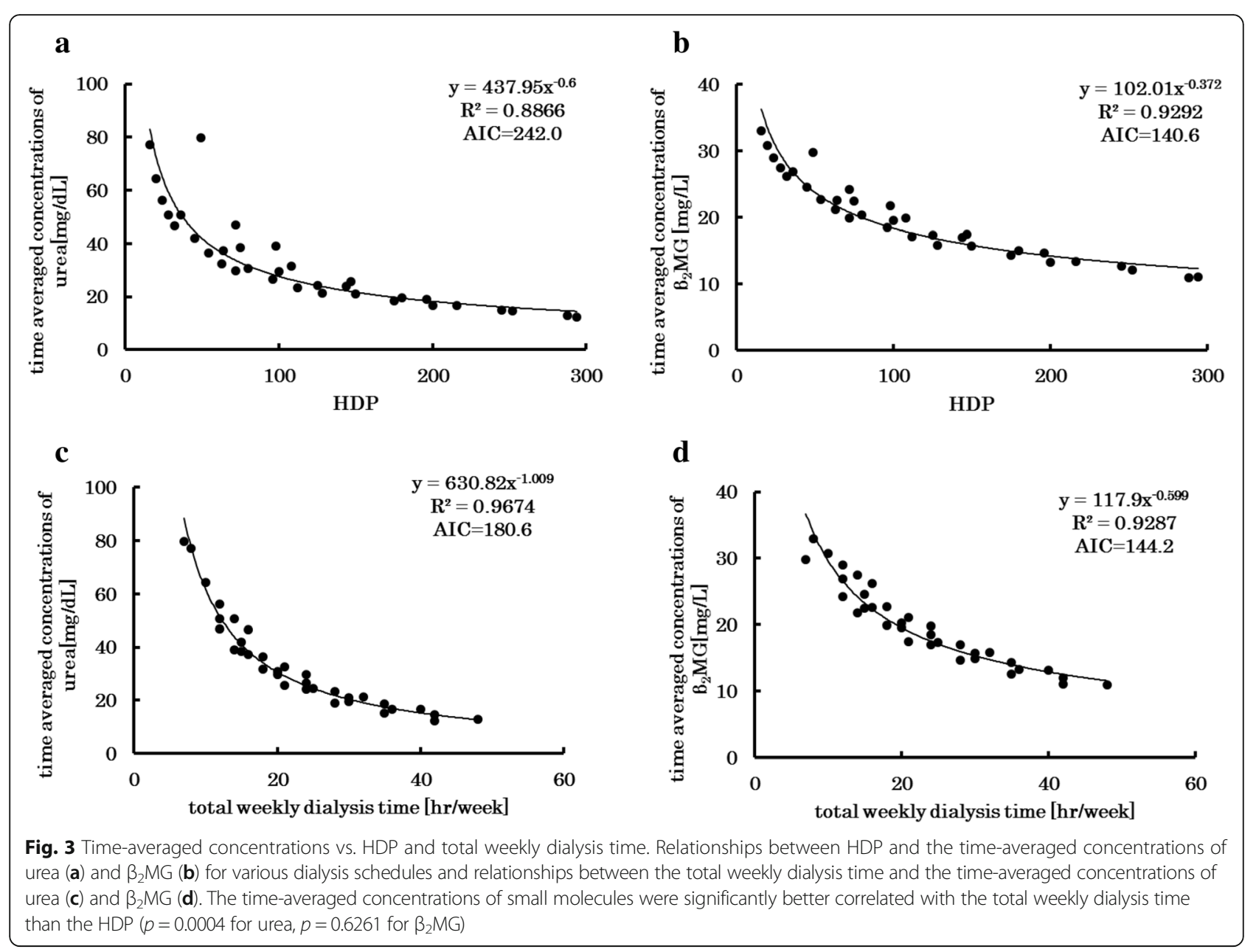

only a few percentage points, which would be expected to have exerted no significant influence on the correlations between the HDP and peak concentration or time-averaged concentration.

The average weekly clearance per week, that is, EKR, is expressed using time-averaged concentration (TAC) and generation rate as [32, 33]:

$$
\mathrm{EKR}=(\mathrm{G} / \mathrm{TAC}) .
$$

If dialysis is performed $n$ times per week with the same clearance, same dialysis time, and same intervals between the dialysis treatments, the concentration changes during the $n$ dialysis sessions per week would be equal and the total removal amount per week can be calculated as:

$$
E K R T_{\mathrm{w}}=n K t,
$$

where $T_{\mathrm{w}}$ is the total number of minutes in the week = $168 \mathrm{~h}$. In actual clinical situations, although the intervals between dialysis treatments are not the same and the TAC is estimated from limited sampled data (the exponential decrease in the concentration was not taken into consideration), we may approximate the above as:

$$
\mathrm{EKR} T_{\mathrm{w}} \fallingdotseq n K t .
$$

This approximation has been shown as a good approximation for thrice-weekly therapy [34]. Therefore, using this approximation:

$$
\mathrm{TAC}=G T_{\mathrm{w}} / n K t=(1 / n t)\left(G T_{\mathrm{w}} / K\right) .
$$

This approximation can lead to a difference from the actual value. The difference is considered to be attributable to the intervals between dialysis treatments being different (therefore, the concentrations at the beginning of each dialysis session are not the same), and the fact that $G, K$, and $V$ cannot be regarded as constant [34].

This equation shows that the time-averaged concentration of urea is inversely proportional to the total dialysis time per week $(n t)$. It is obvious from the theoretical point of view that the time-averaged concentration would be well correlated with the total dialysis time. In the simulation of the present study, we obtained TAC $=630 \mathrm{t}^{-1.0}$ in 

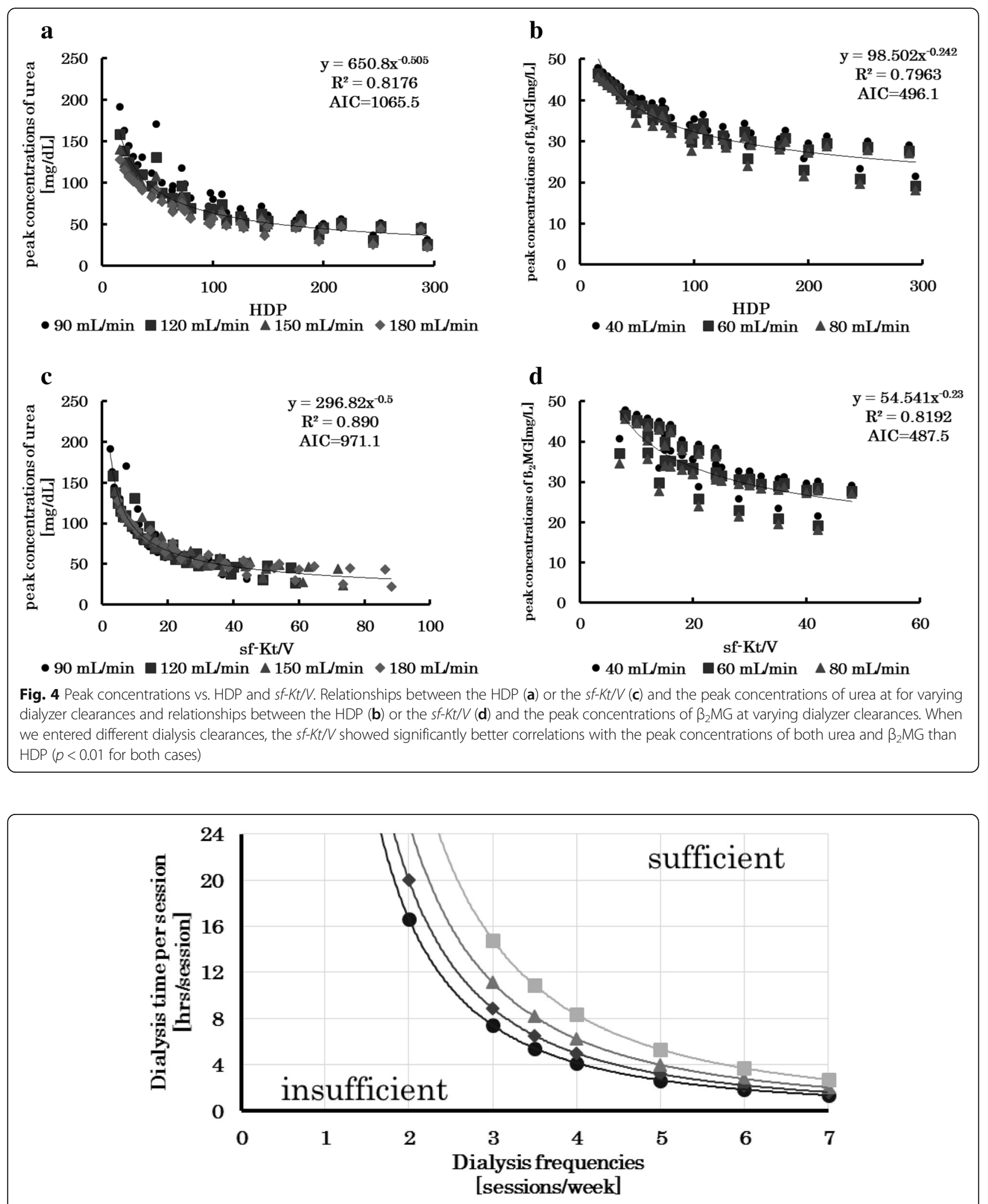

- K: $180 \mathrm{~mL} / \mathrm{min} \bullet \mathrm{K}: 150 \mathrm{~mL} / \mathrm{min} \triangle \mathrm{K}: 120 \mathrm{~mL} / \mathrm{min} \square \mathrm{K}: 90 \mathrm{~mL} / \mathrm{min}$

Fig. 5 Dialysis schedules that would yield $s f-K t / V$ values of over 20 for varying dialyzer clearances at constant $V(V=36,000 \mathrm{~mL})$. Each line shows the schedule that would yield an sf-Kt/V of 20. The area above this line represents the dialysis times/frequencies that yield $s f-K t / V$ values of over 20 . As the dialyzer clearance increases, the dialysis time/frequency needed to obtain an sf-Kt/V value of over 20 decreases 


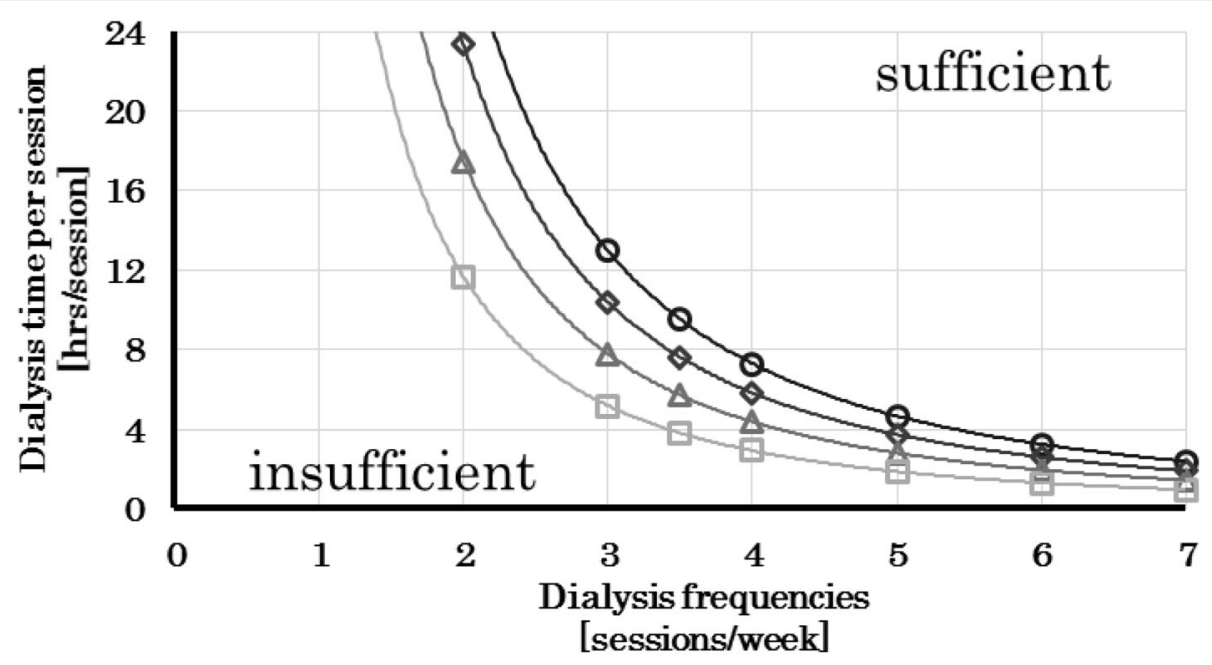

०V: $60 \mathrm{~L} \diamond \mathrm{V}: 48 \mathrm{~L} \Delta \mathrm{V}: 36 \mathrm{~L} \quad \square \mathrm{V}: 24 \mathrm{~L}$

Fig. 6 Dialysis schedules that would yield $s f-K t / V$ values of over 20 for varying body weights of the patient at constant $K$ ( $K=180 \mathrm{~mL} / \mathrm{min})$. Each line shows the schedule that would yield an $s f-K t / V$ value of 20 . The area above this line represents the dialysis times/frequencies that yield $s f-K t / V$ values of over 20. As the body weight of the patient increases, the dialysis time/frequency needed to obtain an sf-Kt/V value of over 20 increases. Thus, the optimal dialysis schedule depends on the patient's body weight

Fig. 2d, implying that the dataset (dialysis frequency and dialysis time for each session) was selected with little bias and the influence of time and frequency of dialysis on the peak concentration and average concentration can be adequately investigated using this dataset.

Therefore, in this study, a new index $s f-K t / V$ was devised considering the factors influencing the peak concentrations, $s f-K t / V=n^{2} K t / V$. The $s f-K t / V$ was established as an indicator showing strong correlations with the peak concentrations. Since $s f-K t / V$ is an indicator based on solute removal that takes the dialyzer clearance and patient's body size into consideration, it can be used to propose a dialysis schedule appropriate for each individual patient and to determine the appropriate dialyzer clearance, dialysis time, dialysis frequency, etc.

Scribner and Oreopoulos recommended HDP $>70$ based on the 30-year excellent survival outcome in Tassin [19-23]. HDP $>70$ is equivalent to $s f-K t / V>20$ when the dialyzer used assumed to have an average urea clearance is $160 \mathrm{~mL} / \mathrm{min}$ and the average dry weight of the patient is $60 \mathrm{~kg}$. Therefore, assuming that HDP $>70$ is a threshold value for determining the adequacy of dialysis, it can be considered that an $s f-K t / V$ value of about 20 for urea may be an approximate threshold of an indicator of the adequacy of dialysis. Currently, there are no data on comparisons of the clinical efficacy using $s f-K t / V$ as an indicator, and we propose to analyze clinical data in the future to establish a satisfactory threshold of $s f-K t / V$. As this threshold value can be determined for each solute, it is necessary to clarify these thresholds not only for urea but also for $\beta_{2}$ MG.

When we calculate $s f-K t / V$, single-pool $K t / V$ can be used for urea and equilibrated $K t / V$ for $\beta_{2}$ MG as $K t / V$. For simple calculation to determine the dialysis schedule, dialysis time, and dialyzer clearance, we can use $K$ as the dialyzer clearance corrected by the blood and dialysate flow rate, $t$ as the dialysis time, and $V$ as the estimated body fluid volume. However, if we use this simple calculation, $s f-K t / V$ would be affected by the differences between the estimated and actual body fluid volume and between the calculated clearance and actual clearance caused by a decrease in the actual blood flow rate or recirculation. Therefore, when conducting cohort studies or randomized controlled trials to determine the threshold value of $s f-K t / V$, it is considered better to use single-pool $K t / V$ for urea and equilibrated $K t / V$ for $\beta_{2}$ MG for the calculation of $s f-K t / V$.

There were several limitations of the present study. This study was not a clinical study. Whether it is indeed an appropriate index is yet to be confirmed by a cohort study

Table 4 Values of the parameters of three-compartment model applied for measured data of $\beta_{2} M G$ in patients [30]

\begin{tabular}{llllllll}
\hline & $V_{1}[\mathrm{~mL} / \mathrm{kg}]$ & $K_{\mathrm{nr}}[\mathrm{mL} / \mathrm{min} / \mathrm{kg}]$ & $V_{2}[\mathrm{~mL} / \mathrm{kg}]$ & $K_{12}[\mathrm{~mL} / \mathrm{min} / \mathrm{kg}]$ & $V_{3}[\mathrm{~mL} / \mathrm{kg}]$ & $K_{13}[\mathrm{~mL} / \mathrm{min} / \mathrm{kg}]$ & $G_{\beta}[\mathrm{mg} / \mathrm{hour} / \mathrm{kg}]$ \\
\hline Mean \pm SD & $53 \pm 9$ & $0.047 \pm 0.010$ & $39 \pm 11$ & $1.25 \pm 0.25$ & $109 \pm 27$ & $0.48 \pm 0.09$ & $0.159 \pm 0.041$ \\
Ratio of SD [\%] & \pm 17 & \pm 21 & \pm 28 & \pm 20 & \pm 25 & \pm 19 & \pm 26 \\
\hline
\end{tabular}

Data were expressed per kg body weight 
Table 5 The percent changes of the peak concentrations determined by the calculation using maximum and minimum value (mean \pm SD) of each parameter shown in Table 3

\begin{tabular}{|c|c|c|c|c|c|c|c|c|c|}
\hline & \multicolumn{2}{|c|}{ Dialysis schedule } & \multicolumn{7}{|c|}{ Percent changes of peak concentrations [\%] } \\
\hline & $n$ & $t$ & $V_{1}$ & $K_{\mathrm{nr}}$ & $V_{2}$ & $K_{12}$ & $V_{3}$ & $K_{13}$ & $G_{\beta}$ \\
\hline \multirow[t]{4}{*}{ Maximum value (mean + SD) } & 2 & 7 & -1.76 & -11.30 & -2.07 & -0.02 & -3.28 & -0.56 & 25.79 \\
\hline & 3 & 4 & -1.69 & -10.61 & -2.09 & -0.06 & -2.80 & -0.69 & 25.77 \\
\hline & 5 & 7 & -2.45 & -6.76 & -3.18 & -0.04 & -4.58 & -1.02 & 25.89 \\
\hline & 7 & 4 & -3.02 & -5.63 & -2.99 & -0.19 & -1.34 & -1.97 & 25.78 \\
\hline \multirow[t]{4}{*}{ Minimum value (Mean - SD) } & 2 & 7 & 1.81 & 13.93 & 2.18 & 0.03 & 4.12 & 0.74 & -25.79 \\
\hline & 3 & 4 & 2.04 & 13.08 & 2.32 & 0.09 & 3.72 & 0.83 & -25.65 \\
\hline & 5 & 7 & 2.98 & 7.67 & 3.66 & 0.06 & 6.27 & 1.45 & -25.77 \\
\hline & 7 & 4 & 3.49 & 6.35 & 3.63 & 0.29 & 2.47 & 2.49 & -25.79 \\
\hline
\end{tabular}

or randomized controlled trial. Furthermore, $s f-K t / V>20$ was also calculated by assuming that HDP $>70$ is the threshold value for determining the adequacy of the dialysis schedule; however, HDP $>70$ has not yet been confirmed by clinical trials whether this threshold value is appropriate or not. When $K=180 \mathrm{~mL} / \mathrm{min}, V=36,000 \mathrm{~mL}$, the dialysis duration that would yield $s f-K t / V$ values of over 20 was calculated as $8 \mathrm{~h}$, meaning $K t / V=2.4$. Current dialysis guidelines for hemodialysis prescription [35] recommend $K t / V=1.4$ or more as the target dose for thrice-weekly dialysis. How to ensure consistency with the current guideline is an important issue while using this index. $s f-K t / V$ is also not a precise index, like the standard $K t / V$ or EKR, and does not reflect the residual kidney function. However, it does reflect the peak concentrations of the accumulated solutes in dialysis patients. With further clinical studies, this index has the potential to become a better indicator for determining the adequacy of dialysis in individual patients.

\section{Conclusions}

The $s f-K t / V$ is an index that takes into account the dialysis frequency, session duration and clearance, and the body weight of the patient and correlates with the peak concentrations more tightly than HDP. It offers the promise of being a very useful index for determining appropriate dialysis schedules and dialysis conditions for individual patients.

\section{Appendix}

\section{Development of a new index and its validation}

Taking into account the results that the peak concentrations of small molecules were better correlated with the HDP than with the total dialysis time and that the HDP has been shown to be well correlated with the clinical symptoms [14], we considered the peak concentrations of small molecules as the candidate factors closely related to the clinical symptoms.

Using a simple kinetic model ignoring changes of the body weight associated with water removal and intake, the concentrations of the solutes just before dialysis for thrice-a-week dialysis were calculated using the following equations:

$$
\begin{aligned}
& C_{1}=C_{0} \exp (-K t / V)+G T_{1} / V \\
& C_{2}=C_{1} \exp (-K t / V)+G T_{2} / V
\end{aligned}
$$

Table 6 The percent changes of time-averaged concentrations determined by the calculation using maximum and minimum value

\begin{tabular}{|c|c|c|c|c|c|c|c|c|c|}
\hline & \multicolumn{2}{|c|}{ Dialysis schedule } & \multicolumn{7}{|c|}{ Percent changes of time-averaged concentration [\%] } \\
\hline & $n$ & $t$ & $\overline{V_{1}}$ & $K_{\mathrm{nr}}$ & $V_{2}$ & $K_{12}$ & $V_{3}$ & $K_{13}$ & $G_{\beta}$ \\
\hline \multirow[t]{4}{*}{ Maximum value (mean $+S D)$} & 2 & 7 & -2.10 & -8.94 & -2.27 & -0.07 & -0.40 & -1.88 & 25.79 \\
\hline & 3 & 4 & -1.88 & -8.92 & -1.89 & -0.18 & 0.65 & -1.75 & 25.75 \\
\hline & 5 & 7 & -2.40 & -4.98 & -2.79 & -0.12 & -0.33 & -2.30 & 25.82 \\
\hline & 7 & 4 & -2.79 & -5.08 & -2.30 & -0.33 & 1.29 & -2.23 & 25.74 \\
\hline \multirow[t]{4}{*}{ Minimum value (mean - SD) } & 2 & 7 & 2.25 & 10.75 & 2.57 & 0.11 & 1.15 & 2.45 & -25.79 \\
\hline & 3 & 4 & 2.36 & 10.85 & 2.40 & 0.30 & -0.56 & 1.96 & -25.76 \\
\hline & 5 & 7 & 2.99 & 5.56 & 3.33 & 0.19 & 1.13 & 3.05 & -25.77 \\
\hline & 7 & 4 & 3.09 & 5.66 & 3.00 & 0.46 & -1.48 & 2.52 & -25.82 \\
\hline
\end{tabular}
(mean \pm SD) of each parameter shown in Table 3 


$$
C_{0}=C_{2} \exp (-K t / V)+G T_{3} / V
$$

where $K$ is the dialysis clearance $[\mathrm{mL} / \mathrm{min}] ; t$ is the dialysis time per session [min]; $T_{1}, T_{2}$, and $T_{3}$ are the interdialysis times; $V$ is the body fluid volume $[\mathrm{mL}]$; and $G$ is the generation of solutes $[\mathrm{mg} / \mathrm{min}]$.

If $T_{3}$ is the maximum dialysis interval, $C_{0}$ becomes the peak concentration per week, $C_{\text {peak }}$ :

$$
C_{\text {peak }}=\frac{\frac{G}{V}\left\{T_{3}+T_{2} \exp -\left(\frac{-K t}{V}\right)+T_{1} \exp \left(\frac{-2 K t}{V}\right)\right\}}{1-\exp \left(\frac{-3 K t}{V}\right)}
$$

Similarly, in the case of four-times-a-week dialysis, the following equation can be obtained.

$$
C_{\text {peak }}=\frac{\frac{G}{V}\left\{T_{4}+T_{3} \exp -\left(\frac{-K t}{V}\right)+T_{2} \exp \left(\frac{-2 K t}{V}\right)+T_{1} \exp -\left(\frac{-3 K t}{V}\right)\right\}}{1-\exp \left(\frac{-4 K t}{V}\right)}
$$

From these equations, in the case of the condition that the $K t / V$ is greater than 1 , the peak concentration, $C_{\text {peak }}$, will become higher when the maximum dialysis interval becomes longer, or when the dialysis frequency $(n)$ decreases or the $K t / V$ becomes less.

Therefore, the peak concentration would be well correlated with:

$$
n\left(\frac{K t}{V}\right)\left(\frac{1}{T_{\max }}\right)
$$

where $T_{\max }$ is the maximum interval between dialysis sessions [h].

This can be arranged into a dimensionless form as $n\left(\frac{K t}{V}\right)$ $\left(\frac{T_{\mathrm{w}}}{T_{\max }}\right)$

This index should be well correlated with the $C_{\text {peak }}$. If the intervals between dialysis sessions are equal, then:

$$
T_{\max } \fallingdotseq \frac{T_{\mathrm{w}}}{n},
$$

and the following equation can be obtained.

$$
n\left(\frac{K t}{V}\right)\left(\frac{T_{\mathrm{w}}}{T_{\max }}\right) \fallingdotseq n^{2}\left(\frac{K t}{V}\right)=n^{2} t\left(\frac{K}{V}\right)
$$

Because HDP $=n^{2} t$, it is easy to conceive why the peak concentrations of small molecule solutes are well correlated with the HDP as well as this index. This index incorporates both solute removal $(K)$ and fluid volume of the patient $(V)$, whereas the HDP does not. Therefore, this index can be used more flexibly, and we propose this index as a new index called squared frequency-Kt/V $(s f-K t / V)$.

\section{Abbreviations}

AIC: Akaike Information Criterion; $C_{B}$ : Blood level $[\mathrm{mg} / \mathrm{mL}] ; C_{\text {peak }}$ : Peak concentration per week $[\mathrm{mg} / \mathrm{mL}]$; EKR: Average weekly clearance per week $[\mathrm{mL} / \mathrm{min}] ; G_{\Perp}$ : Endogenous production rate of urea $[\mathrm{mg} / \mathrm{min}]$;

$G_{\beta}$ : Endogenous production rate of $\beta_{2}$-microglobulin $[\mathrm{mg} / \mathrm{min}]$; HDP: Hemodialysis product; $K$ : Dialysis clearance $[\mathrm{mL} / \mathrm{min}] ; K_{\mathrm{d}}$ : Dialyzer clearance $[\mathrm{mL} / \mathrm{min}] ; K_{\mathrm{nr}}$ : Non-renal clearance $[\mathrm{mL} / \mathrm{min}] ; K_{\mathrm{r}}$ : Renal clearance $[\mathrm{mL} / \mathrm{min}] ; K_{\mathrm{u}}$ : Clearance of urea $[\mathrm{mL} / \mathrm{min}] ;$ L: Likelihood; $n$ : Dialysis frequency [sessions/week]; N: Sample size; $R^{2}$ : Coefficients of determination; sf-Kt/ $V$ : Squared frequency-Kt/V; $t$ : Dialysis time per session for HDP [h/session]; $t$ : Dialysis time per session [min/session]; $T_{1}, T_{2}, T_{3}$ : Inter-dialysis times [min]; TAC: Time-averaged concentration $[\mathrm{mg} / \mathrm{mL}] ; T_{w}$ : Total number of minutes in a week (10,080 min) [min]; V: Body fluid volume $[\mathrm{mL}] ; V_{1}, V_{2}, V_{3}$ : Volume of compartments 1,2 , and 3 per body weight $[\mathrm{mL} / \mathrm{kg}] ; V_{\mathrm{d}}$ : The sum of the compartmental volumes $[\mathrm{mL}] ; \beta_{2} M G$ : $\beta_{2}$-microglobulin; $\sigma^{2}$ : Maximum likelihood estimator of variance

\section{Acknowledgements}

Not applicable.

\section{Funding}

Institutional research fund.

\section{Availability of data and materials}

Not applicable.

\section{Authors' contributions}

KM provided the research design, carried out the simulation and data analysis, and wrote the manuscript. KeKo provided the working hypothesis, participated in the research design, and wrote the manuscript. $\mathrm{MH}$ and KoKo participated in the research design and substantially contributed to the study concept. HK provided the working hypothesis, participated in the research design, and substantially contributed to the study concept. All authors read and approved the final manuscript.

Ethics approval and consent to participate Not applicable.

\section{Consent for publication}

Not applicable.

\section{Competing interests}

The authors declare that they have no competing interests.

\section{Publisher's Note}

Springer Nature remains neutral with regard to jurisdictional claims in published maps and institutional affiliations.

\section{Author details}

${ }^{1}$ Kitasato University Graduate School of Medical Sciences, Sagamihara, Japan. ${ }^{2}$ Kitasato University School of Allied Health Sciences, Sagamihara, Japan. ${ }^{3}$ Department of Medical Engineering and Technology, Kitasato University School of Allied Health Sciences, 1-15-1 Kitasato, Minami-ku, Sagamihara, Kanagawa 252-0373, Japan.

Received: 27 September 2018 Accepted: 8 January 2019 Published online: 19 February 2019

\section{References}

1. Kjellstrand CM, Buoncristiani U, Ting G, Traeger J, Piccoli GB, Sibai-Galland R, et al. Short daily haemodialysis: survival in 415 patients treated for 1006 patient-years. Nephrol Dial Transplant. 2008;23:3283-9.

2. Pierratos A, Ouwendyk M, Francoeur R, Vas S, Raj DS, Ecclestone AM, et al. Nocturnal hemodialysis: three-year experience. J Am Soc Nephrol. 1998;9:859-68.

3. Pierratos A. Nocturnal home haemodialysis: an update on a 5-year experience. Nephrol Dial Transplant. 1999;14:2835-40.

4. Culleton BF, Walsh M, Klarenbach SW, Mortis G, Scott-Douglas N, Quinn RR, et al. Effect of frequent nocturnal hemodialysis vs conventional hemodialysis on left ventricular mass and quality of life. JAMA. 2007;298:1291-9. 
5. Agar JW, Knight RJ, Simmonds RE, Boddington JM, Waldron CM, Somerville CA. Nocturnal haemodialysis: an Australian cost comparison with conventional satellite haemodialysis. Nephrology (Carlton). 2005;10:557-70.

6. Pierratos A. Daily nocturnal home hemodialysis. Kidney Int. 2004;65:1975-86.

7. Mowatt G, Vale L, MacLeod A. Systematic review of the effectiveness of home versus hospital or satellite unit hemodialysis for people with endstage renal failure. Int J Technol Assess Health Care. 2004;20:258-68.

8. Oberley ET, Schatell DR. Home hemodialysis: survival, quality of life, and rehabilitation. Adv Ren Replace Ther. 1996;3:147-53.

9. Gotch FA. The current place of urea kinetic modelling with respect to different dialysis modalities. Nephrol Dial Transplant. 1998;13(Suppl 6):S10-4.

10. Leypoldt JK, Jaber BL, Zimmerman DL. Predicting treatment dose for novel therapies using urea standard Kt/N. Semin Dial. 2004;17:142-5.

11. Diaz-Buxo JA, Loredo JP. Standard Kt/N: comparison of calculation methods. Artif Organs. 2006;30:178-85

12. National Kidney Foundation. KDOQI Clinical Practice Guidelines and Clinical Practice Recommendations for 2006 updates: hemodialysis adequacy, peritoneal dialysis adequacy and vascular access. Am J Kidney Dis. 2006; 48(Suppl 1):S1-S322

13. National Kidney Foundation. KDOQI Clinical Practice Guideline for Hemodialysis Adequacy: 2015 update. Am J Kidney Dis. 2015;66:884-930.

14. Scribner BH, Oreopoulos DG. The hemodialysis product (HDP): a better index of dialysis adequacy than Kt/N. Dialysis \& Transplantation. 2002;31:13-5.

15. DePalma JR, Pecker EA, Maxwell MH. A new automatic coil dialyser system for "daily" dialysis. Hemodial Int. 2004;8:19-23.

16. Buoncristiani U, Quintaliani G, Cozzari M, Giombini L, Ragaiolo M. Daily dialysis: long-term clinical metabolic results. Kidney Int. 1988;33(Suppl 24):S137-40.

17. Bonomini V, Mioli V, Albertazzi A, Scolari P. Daily-dialysis programme: indications and results. Nephrol Dial Transplant. 1998;13:2774-7.

18. Lockridge RS, Albert J, Anderson H, Barger T, Coffey L, Craft V, et al. Nightly home hemodialysis: fifteen months of experience in Lynchburg, Virginia. Home Hemodialysis Int. 1999;3:23-8.

19. Charra B, Calemard E, Cuche M, Laurent G. Control of hypertension and prolonged survival on maintenance hemodialysis. Nephron. 1983;33:96-9.

20. Charra B, Calemard E, Ruffet M, Chazot C, Terrat JC, Vanel T, et al. Survival as an index of adequacy of dialysis. Kidney Int. 1992;41:1286-91.

21. Charra B, Chazot C, Jean G, Laurent G. Long, slow dialysis. Miner Electrolyte Metab. 1999;25:391-6.

22. Charra B, Laurent G. Long hemodialysis: the key to survival? In: Brown EA, Parfrey PS, editors. Complications of long-term dialysis. Oxford: Oxford University Press; 1999. p. 228-56.

23. Laurent $\mathrm{G}$, Calemard $\mathrm{E}$, Charra B. Long dialysis: a review of fifteen years experience in one centre 1968-1983. Proc Eur Dial Transplant Assoc. 1983;20:122-35.

24. The FHN Trial Group. In-center hemodialysis six times per week versus three times per week. N Engl J Med. 2010;363:2287-300.

25. Woods JD, Port FK, Orzol S, Buoncristiani U, Young E, Wolfe RA, et al. Clinical and biochemical correlates of starting "daily" hemodialysis. Kidney Int. 1999; 55:2467-76.

26. Ok E, Duman S, Asci G, Tumuklu M, Onen Sertoz O, Kayikcioglu M, et al. Comparison of 4-and 8-h dialysis sessions in thrice-weekly in-centre haemodialysis: a prospective, case-controlled study. Nephrol Dial Transplant. 2011;26:1287-96.

27. Lacson E Jr, Xu J, Suri RS, Nesrallah G, Lindsay R, Garg AX, et al. Survival with three-times weekly in-center nocturnal versus conventional hemodialysis. J Am Soc Nephrol. 2012;23:687-95.

28. Culleton BF, Asola MR. The impact of short daily and nocturnal hemodialysis on quality of life, cardiovascular risk and survival. J Nephrol. 2011;24:405-15.

29. Sargent JA, Gotch FA. The analysis of concentration dependence of uremic lesions in clinical studies. Kidney Int. 1975;7(Suppl 2):S35-44.

30. Odell RA, Slowiaczek P, Moran JE. Beta2-microglobulin kinetics in end-stage renal failure. Kidney Int. 1991;39:909-19.

31. Begg EJ, Barclay ML, Kirkpatrick CJ. The therapeutic monitoring of antimicrobial agents. Br J Clin Pharmacol. 1999;47:23-30.

32. Popovich RP, Moncrief JW. In: Nolph KD, editor. Transport kinetics. Peritoneal dialysis, ed. by, vol. 115. Boston: Martinus Nijhoff Publication; 1985.

33. Mineshima M, Suzuki T, Sudo N, Takemoto M, Agishi T, Ota K, et al. Solute removal dynamics in CAPD. Jpn J. Dialysis Therapy. 1983;16:321-4 (Article in Japanese).
34. Mineshima M, Hoshino T, Era K, Nakazato S, Kubo K, Sanaka T, et al. Validity of 1-compartment model for urea on adequate dialysis. Jpn J Artif Organs. 1993;22:320-4 (Article in Japanese).

35. Watanabe Y, Kawanishi H, Suzuki K, Nakai S, Tsuchida K, Tabei K, et al. Japanese Society for Dialysis Therapy Clinical Guideline for "maintenance hemodialysis: hemodialysis prescriptions". Ther Apher Dial. 2015;19(Suppl 1): 67-92.
Ready to submit your research? Choose BMC and benefit from:

- fast, convenient online submission

- thorough peer review by experienced researchers in your field

- rapid publication on acceptance

- support for research data, including large and complex data types

- gold Open Access which fosters wider collaboration and increased citations

- maximum visibility for your research: over $100 \mathrm{M}$ website views per year

At $\mathrm{BMC}$, research is always in progress.

Learn more biomedcentral.com/submissions 